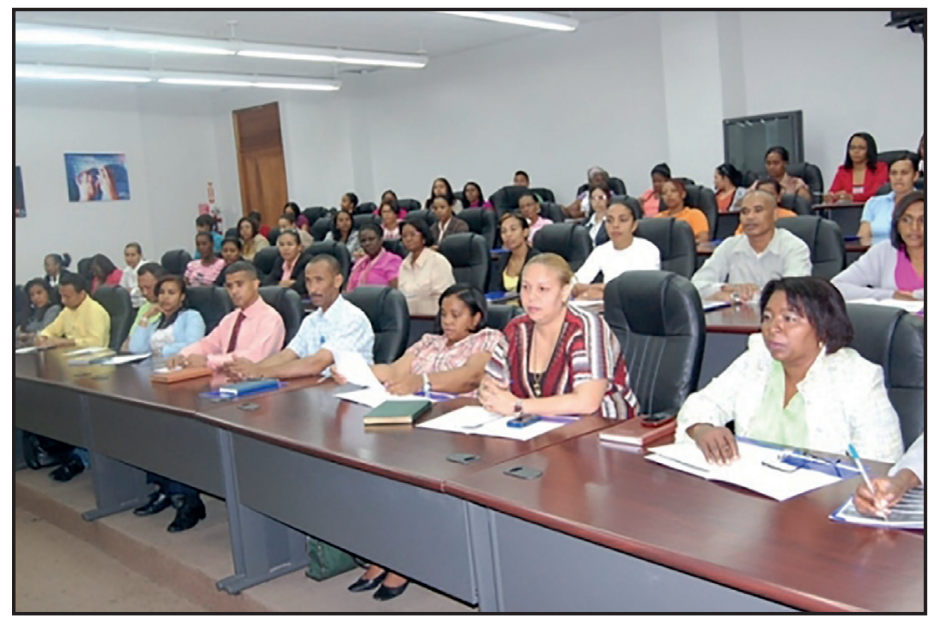

http://www.inafocam.edu.do/portal/index.php/noticias-inafocam/item/592inafocam-e-itla-inician-segunda-etapa-del-diplomado-docente-tecnologico.html

\title{
EDUCACIÓN Y DEMOCRACIA
}

\section{Laso Bayas, Ramiro}

Rodas Reinbach, Diana Lee

Correspondencia: rlaso@uazuay.edu.ec;

dianaleerodas@uazuay.edu.ec

“... MIENTRAS VIVAMOS, MIENTRAS ESTEMOS ENTRE LOS SERES HUMANOS, CULTIVEMOS NUESTRA HUMANIDAD"

SÉneCA. Sobre LA IRA 


\section{Resumen}

Vivimos en medio de una crisis de grandes proporciones y de enorme gravedad mundial. La educación actual no ayuda a ser hombres de costumbres democráticas. Pensamos y asumimos todo aquello que genera ganancias inmediatas o beneficios prácticos. Es más, se ha establecido un ambiente educativo que es bueno en la medida en que contribuye a mis propios intereses y me ayude a conseguir lo que sea y a cómo de lugar. Se excluye la formación de un ser humano que busque el bien común y se imponen ideas y formas únicas de pensar y educar. Grandes profesionales pero pésimos ciudadanos. ¿Democracia? Por ningún lado.

Palabras clave: Educación, universidad, democracia, sociedad disciplinaria.

\section{EDUCATION AND DEMOCRACY}

\section{Abstract}

We live in the midst of a number of world crises of great proportions and of enormous seriousness. Today's educational process does not help people within the democratic traditions. We think and assume those things that generate immediate gains or practical benefits. Furthermore, an educational environment that is considered good as long as it contributes to my own interests and helps me achieve what I want, and at any cost, has been established. This excludes the values of a human being who seeks the common good; and ideas and unique ways of thinking and of education are imposed. Great professionals but bad citizens. ¿democracy? Nowhere!

Keywords: Education, university, democracy, disciplinary society. 
Rabindranath Tagore, en el Nacionalismo, año 1917, citado por Nussbaum, 2012, provocaba esta reflexión que nos introduce en el punto fundamental de este escrito:

"La historia ha llegado a un punto en el que el hombre moral, el hombre íntegro, está cediendo cada vez más espacio, casi sin saberlo (...) al hombre comercial, el hombre limitado a un solo fin. Este proceso, asistido por las maravillas del avance científico, está alcanzando proporciones gigantescas, como un poder inmenso, lo que causa el desequilibrio moral del hombre y oscurece su costado más humano bajo la sombra de una organización sin alma" (pág. 7).

Vivimos en medio de una crisis de grandes proporciones y de enorme gravedad mundial. Crisis que para muchos pasa inadvertida pero que en la realidad significa un cáncer para la sociedad: la educación actual no ayuda a ser hombres de costumbres democráticas. Y, por lo tanto, el futuro de la humanidad se verá envuelto -si ya no lo está- en aspectos puramente comerciales y de generación económica donde lo único que interesa es la obtención de la renta en un mundo globalizado. Codicia y narcisismo combaten el respeto y la creación de una cultura mundial digna. Se alimenta la violencia y deshumanización, en lugar de alimentar las fuerzas que impulsan la cultura de la igualdad y el respeto. (Nussbaum, 2012, pág. 189).

\section{La utilidad de lo inútil}

Nuccio Ordine propone el título de su libro desde la frase que encabeza este apartado. Merece la pena apreciar sobremanera el ensayo. Todo lo que hagamos 
o dejemos de hacer por educar en lo que él llama 'inútil porque no tiene utilidad económica' redundará en una mejor o peor opción democrática.

El libro, dice el autor, evocado como un oxímoron, necesita una aclaración. "La paradójica utilidad a la que me refiero no es la misma en cuyo nombre se consideran inútiles los saberes humanísticos y, más en general, todos los saberes que no producen beneficios". Las reflexiones transcurren en la medida en que, la idea de utilidad cobra sentido en aquellos saberes cuyo valor esencial es del todo ajeno a cualquier finalidad utilitarista. Lo inútil, en cambio, es todo aquello que no genera ganancias inmediatas o beneficios prácticos. Porque, por supuesto, en este mundo súper productor y utilitarista, "un martillo vale más que una sinfonía, un cuchillo más que una poesía, una llave inglesa más que un cuadro: porque es fácil hacerse cargo de la eficacia de un utensilio mientras que resulta cada vez más difícil entender para qué pueden servir la música, la literatura o el arte". (2014, pág. 12).

Ya nos lo recuerda el autor desde la frase de Rousseau cuando había notado que "los antiguos políticos hablaban incesantemente de costumbres y virtudes; los nuestros sólo hablan de comercio y de dinero".

El ensayo tiene como objetivo recoger citas y pensamientos que, a lo largo de muchos años de enseñanza e investigación, proponen lo que él reafirma como utilidad de lo inútil.

Tres partes tiene el escrito: la primera, dedicada al tema de la útil inutilidad de la literatura; la segunda, a mirar los efectos desastrosos de la lógica del beneficio en el 
campo de la enseñanza, especialmente en la universidad. De hecho, lo titula como Universidad-empresa y los estudiantes-clientes. Capítulo que nos viene como anillo al dedo y que ha sido el punto de partida para conocer más y mejor a autores como Martha Nussbaum y los clásicos tratadistas: Víctor Hugo, Tocqueville, Herzen, Bataille, John Henry Newman, John Locke, Poincaré. Todos a una sola voz, reafirmando la belleza y gozo que produce el estudio de la naturaleza, no porque sea útil, sino porque simplemente es bella. Porque si no lo fuera no valdría la pena ni conocerla ni vivir la vida (2014, pág. 110). Y, la tercera, la presentación de la relectura de algunos clásicos que han denunciado constantemente la violencia que se ejerce contra la dignidad del hombre, la verdad y la belleza cuando la posesión se constituye en valor fundamental de la sociedad. Es "el gozar, no el poseer, lo que nos hace felices" sugería Montaigne.

Propone al final un texto de Abraham Flexner, publicado en 1939, donde detalla cómo precisamente los saberes inútiles, considerados como teóricos, son los que han favorecido de forma inesperada aplicaciones que se han revelado fundamentales para el género humano. Hermosa proposición final que derriba prejuicios cientistas y utilitaristas.

Se hace tan indispensable esta lectura, así como, apasionante el querer proponer unas líneas que sinteticen la mirada de una educación que tenga como norte la utilidad de lo inútil. Lo vamos a intentar. Será el primer paso de dos, desde donde planteamos la relación educacióndemocracia. 


\section{El primero, la construcción de la sociedad desde la propuesta económico-comercial. Sociedad y democracia economicistas.}

Los estudiantes ya no son estudiantes, buscadores del conocimiento, sino simples clientes. En Harvard, por ejemplo, citando a Jaffelin (Le Monde 28-05-2012), Ordine dice que "dado que se paga muy cara la matrícula...el estudiante no solo espera de su profesor que sea docto, competente y eficaz: espera que sea sumiso, porque el cliente siempre tiene la razón". Y se lo explicita a través de un estilo donde las universidades venden los diplomas y los grados, ofreciendo cursos y programas con la promesa de obtener trabajos inmediatos y atractivos ingresos (2014, pág. 79). Y a la universidad, como institución, se la ha transformado en empresa: hay que producir para insertarse en el mundo laboral; y producir es sacar productos: profesores burócratas al servicio de la gestión empresarial; jornadas llenas de papeles y expedientes que evidencian el trabajo, informes, estadísticas, intentando cuadrar las cuentas; a estole llama el metrónomo burocrático, que regula absolutamente la vida universitaria. Y la investigación... y el estudio: el profesor es un infatigable estudiante, cosa de la que se olvida fácilmente el empresario universitario. Y la preparación de clases, convertida en un lujo que hay que negociar con los directivos institucionales. $Y$ los alumnos... Será que la tarea universitaria puede reducirse a formar médicos, ingenieros o abogados, privilegiando la exclusiva profesionalización en detrimento de la curiosidad, asombro, búsqueda del conocimiento y sabiduría..., imaginando de forma imposible ciudadanos responsables, capaces de abandonar los propios egoísmos para abrazar 
el bien común, para expresar la solidaridad, la tolerancia, la libertad, proteger la naturaleza y apoyar la justicia... construyendo democracia. (2014, págs. 80-82).

De entre los muchos autores que cita expresamente para fundamentar su tesis en este capítulo, Ordine descubre el pensamiento de Víctor Hugo y de John Henry Newman. Dos visiones diferentes; pero complementarias para saborear la utilidad de lo inútil.

El primero, desde las letras con afanes políticos, cuando en un discurso que pronunció a la Asamblea constituyente, en noviembre de 1848, demandó como perjudicial e ineficaz la disminución de los recursos para la cultura, saberes y educación para los jóvenes porque de esa manera la sociedad caería en el abismo de la ignorancia. No basta "con proveer la iluminación de las ciudades", pues "también puede hacerse de noche en el mundo moral". Quién proveerá a encender "antorchas para las mentes". (2014, pág. 84).

Y, el segundo, John Henry Newman, educador total, visionario y diseñador de la universidad inglesa, quien expresamente propuso la idea de 'campus' universitario como el lugar del regocijo académico y cuyos ensayos entre otras cosas- rechazan el utilitarismo de la formación universitaria (Gutiérrez Lozano, 2013, págs. 170-171)1. No puede ser buscado sólo lo útil porque se caería en

Para Gutiérrez Lozano, parafraseando a Newman, "La universidad es el lugar donde todos los saberes tienen su lugar... Una universidad que no permita todos los saberes se descalifica automáticamente como tal...La Universidad es el lugar donde las ciencias conviven en orden y armonía unas con otras, teniendo como árbitro y juez la verdad". (2013, pág. 171). 
trivialidades; tampoco puede ser posible que se vea la educación como útil si solo se dedica a una formación práctica, actividad técnica o algún secreto de la física. Newman reafirma la importancia del saber en sí como gran bien, porque éste impartirá un gran bien. (2014, págs. 9193).

"Sólo el saber, dice el autor -cuestionando los paradigmas dominantes del beneficio-, puede ser compartido sin empobrecer. Al contrario, enriqueciendo a quien lo transmite y a quien lo recibe" (2014, pág. 111). El conocimiento es una riqueza que no la brinda la utilidad. La única riqueza que no empobrece ni divide, sino que fortalece y amalgama al ser humano. Y para esto, está la universidad. Y esto es la universidad: "el lugar que enseña saber universal”, democracia. (Gutiérrez Lozano, 2013, pág. 170).

De la misma manera y en distinto tono, lo dicen y reflexionan Martha C. Nussbaum e Iván Carvajal. La primera afirma que la educación democrática está entre las cuerdas en la medida en que "la presión por lograr el crecimiento económico ha llevado a muchos líderes políticos de Europa a reformular la totalidad de la educación universitaria en términos orientados hacia el crecimiento, indagando acerca de cuál es la contribución que hacen a la economía cada una de las disciplinas e investigadores" (2012, pág. 169). Se debe demostrar qué aportes hacen a la economía y rentabilidad la docencia e investigación, las áreas dedicadas a las humanidades. Resalta en la conclusión del libro, que "si no insistimos en la importancia fundamental de las artes y humanidades, éstas desaparecerán, porque no sirven para ganar dinero" (2012, pág. 189). Más todavía, que sólo sirven "para algo 
mucho más valioso: para formar un mundo en el que valga la pena vivir, con personas capaces de ver a los otros seres humanos como entidades en sí mismas, merecedoras de respeto y empatía, que tienen sus propios pensamientos y sentimientos, y también con naciones capaces de superar el miedo y la desconfianza en pro de un debate signado por la razón y la compasión". (2012, pág. 189).

Para Carvajal, en cambio, es tan fuerte el cambio producido con la escisión del conocimiento en las universidades que el saber humanístico, sin fines de lucro en función de la comprensión del lugar del ser humano en la tierra ha sido desplazado completamente por el saber científico determinado por las tecnologías y el arrogante dominio del hombre a través del capital. "Desde esta perspectiva, dice Carvajal, el horizonte en el que al parecer tendrían que pensar su misión las universidades (...) depende más de la economía que de la comprensión del mundo y del lugar del ser humano en él”. (2016, pág. 200).

\section{El segundo, la democracia y la educación vistas como disciplina, poder, castigo: control.}

Es oportuno reflexionar sobre el pensamiento de Foucault; primero porque sustancialmente es una propuesta crítica a las personas y sociedades pasada y actual con todas sus instituciones incluidas. Y lo segundo, porque siempre es grato analizar Vigilar y castigar como una de las obras desde las cuales la 'disciplina' es el eje fundamental de la educación y que -en sometimiento totallas personas respondan a la mejor organización que ha existido para el control del poder. Tipo de educación que quiebra por completo la mirada de la democracia. 
Nos detenemos en dos puntos: el primero, la relación de esta sociedad disciplinaria con el poder, establecida en la práctica, en la norma y en el saber; una sociedad disciplinaria transformada en sociedad de control; y el segundo, cómo esa manera de ser se refleja en la educación.

\section{Sociedad disciplinaria y poder}

Mirar la sociedad desde el poder significa observar la capacidad de los seres humanos por lograr siempre que el otro me obedezca: desde el sometimiento y la capacidad de sojuzgar por la fuerza hasta la producción de un poder que crea una forma de vida a través de una ideología.

Fijémonos en que hay una intención profunda. En el tema del suplicio, desarrollado por Foucault en Vigilar $y$ castigar, siempre se refleja aquello de que se castiga y vigila encaminándose a lo más profundo y desde lo más profundo: "A la expiación que causa estragos en el cuerpo debe suceder un castigo que actúe en profundidad sobre el corazón, el pensamiento, la voluntad, las disposiciones" (1978, pág. 24). "El alma del delincuente no se invoca en el tribunal a los únicos fines de explicar su delito... se la convoca para juzgarla... y para tomarla a cargo en el castigo". (1978, págs. 25-26).

Bajo cierta benignidad de actuación o bajo sometimiento brutal, los seres humanos hemos ejercido el poder: "el cuerpo sólo se convierte en fuerza útil cuando es a la vez cuerpo productivo y cuerpo sometido". (1978, pág. 34).

Según el autor, el poder ejerce el poder, produce, es decir, propone, discurre, multiplica dispositivos, 
organismos, artificios, funciones, tácticas, mecanismos, todo en función de ejercer el poder -aunque redundante- a través de formas de práctica social.

- Quizás haya que renunciar a creer que el poder vuelve loco, y que, en cambio, la renunciación al poder es una de las condiciones con las cuales se puede llegar a sabio. Hay que admitir más bien que el poder produce saber...; que poder y saber se implican directamente el uno al otro; que no existe relación de poder sin constitución correlativa de un campo de saber, ni de saber que no suponga y no constituya al mismo tiempo unas relaciones de poder". (1978, pág. 34).

Entre el poder y el saber existe una unidad indisoluble, porque todo saber responde a un poder o a una forma de obediencia que somete. "El poder considerado abstractamente, no 've' ni 'habla'... se ejerce a partir de innumerables puntos... viene de abajo. Pero precisamente porque ni habla ni ve, hace ver y hablar"2.

A pesar del carácter disciplinario del poder, Foucault destaca el carácter productivo del poder: "lo que le da estabilidad al poder, lo que induce a tolerarlo, es el hecho de que no actúa solamente como una potencia que dice no, sino que también atraviesa las cosas, las produce, suscita placeres, forma saberes, produce discursos"3.

Cora Escolar, investigadora de la universidad de Buenos Aires, cuando piensa en/con Foucault, subraya -a 2 Cita propuesta por Cora Escolar en el artículo sobre Deleuze, G. La obra se refiere a Foucault. Barcelona: Paidós Studio, 1986,111.

3 Cora Escolar, citando a Foucault en La voluntad de Saber, a partir de su artículo Pensar en/con Foucault, 3. 
través de las palabras del pensador- la relación del poder y su producción de poder: "Cuando pienso en la mecánica del poder, pienso en su forma capilar de existir, en el proceso por medio del cual el poder se mete en la misma piel de los individuos, invadiendo sus gestos, sus actitudes, sus discursos, sus experiencias, su vida cotidiana" y, continúa: "es preciso dejar de describir siempre los efectos del poder en términos negativos: 'excluye', 'reprime', 'rehúsa', 'abstrae', 'encubre', 'oculta', 'censura'. En efecto, el poder produce, produce lo real, produce campos de objetos y rituales de verdad..."4.

También es importante y la autora nos ayuda a colegir que, "si el poder produce poder, éste se establece y diseña a través de la disciplina, a través de la norma. La norma es precisamente aquello por lo que la sociedad, cuando se hace disciplinaria, se comunica consigo misma. La norma articula las instituciones disciplinarias de producción, de saber, de riqueza, de finanzas y las hace interdisciplinarias, convierte en inteligible el espacio social”. (2004, pág. 3). Dice Foucault:

"Tradicionalmente el poder es lo que se ve, lo que se muestra, lo que se manifiesta,... Aquellos sobre quienes se ejerce el poder pueden permanecer en la sombra; sólo reciben la luz que les es concedida de esta parte del poder... En la disciplina, son los sujetos quienes han de ser vistos. Esta iluminación asegura el dominio del poder que se ejerce sobre ellos". (1978, pág. 65).

En palabras de García Canal esta es la sociedad disciplinaria que tiene que ser considerada como una $4 \quad$ La autora del artículo está citando a Foucault desde Vigilar y castigar y cuando trata el tema de La Práctica del Poder. México: Siglo XXI, 1975.

282 
colonia penitenciaria, con múltiples máquinas productoras de sujetos que aprenden el sometimiento a través de hábitos, respuestas inconscientes a normas y saberes: sociedad que más que reprimir, forma, conforma y habitúa. Sociedad donde se mezcla poder que produce, norma que ejecuta y saber como forma de obediencia.

La sociedad moderna trabaja el cuerpo antes que el pensamiento, y merced a su capacidad de modelar los cuerpos puede producir en ellos una forma de ser y de pensar. La sociedad moderna desarrolla una tecnología más que una ideología... es una máquina de producción de sujetos... y, en tanto disciplina se convierte en su técnica privilegiada utilizada desde el nacimiento hasta la misma muerte, sobre los cuerpos de los sujetos. (2011, pág. 1).

\section{Sociedad disciplinaria y educación}

La sociedad disciplinaria ejercida en la sociedad moderna tiene una forma nueva de ejercer el poder y de producir el poder: es la sociedad de control, como un orden social distinto y que está acarreando novedosos vientos de poder. Hoy la clásica representación del poder, basada en la idea del panóptico unidireccional, ya no sirve para explicar la forma en que es ejercida la vigilancia. (Requena Hidalgo, 2004, pág. 1).

La incorporación de nuevas tecnologías mantiene al poder y al ejercicio del poder de forma más sofisticada. Especialmente la escuela o el ejercicio educativo en general, se ve obligado a ejercer la 'inspección' o principio fundamental del panóptico de otra manera ${ }^{5}$.

$5 \quad$ La idea de 'panóptico' confluye en ser mirados. Incluso, se 
Veamos primero esta nueva forma de dominación en la sociedad en general:

Lo que ocurre ahora, esta representación del poder, siglos XIX y buena parte del XX..., no resulta operativa para explicar las realidades del mundo a principios del siglo XXI. A causa de los profundos cambios sociales (tecnológicos, económicos y culturales) se precisa otra representación del poder y hablar, más que de un Estado de vigilancia, de una sociedad de vigilancia en la que se daría un entramado muy diferente del poder y en la que su impacto en la autoridad, en la cultura, en la sociedad y en la política sería muy distintos del poder centralizado que tenía en nuestro pasado inmediato. Ahora, la visibilidad sobre los individuos es el resultado de multitud de "miradas", todas de procedencias y direcciones diferentes, con intereses diferentes... Cada vez que hacemos una compra, pasamos por un peaje, asistimos al médico, nos conectamos a Internet o llamamos por teléfono quedamos brevemente iluminados por un panóptico, en efecto, pero un panóptico distinto: un panóptico ubicuo y descentralizado por completo. Las nuevas tecnologías ofrecen la posibilidad de una vigilancia omnisciente, real y efectiva, no fingida o posible; el antiguo inspector ha sido sustituido por una multitud de inspectores, que pueden operar de forma coordinada o compitiendo entre ellos; y lo más importante: su potencia, infinitamente superior, reside en que cuenta con la participación voluntaria de la gente, que ya no es necesario fijar y aislar mediante la coerción. (Requena Hidalgo, 2004, pág. 7).

hace tan carne de la persona, que es el mismo individuo el que - sin necesidad de estar vigilado- se siente vigilado. El vigilante es uno mismo. 
Cita larga pero importante. La sociedad moderna ha dejado atrás la sociedad disciplinaria y ha entrado en la llamada sociedad de control, que funciona por medio de un control continuo y una comunicación instantánea.

Imaginémonos una sociedad educativa bajo el acecho y producción del poder desde algunos sistemas tecnológicos -panópticos que constituyen la columna vertebral del poder: sistemas biométricos; sistemas de observación de personas, lugares o situaciones; los sistemas imaging, para codificar o decodificar la información oculta en imágenes o lugares; los sistemas de comunicación; los sistemas de apoyo a la toma de decisiones; las bases de datos. (Requena Hidalgo, 2004, pág. 7).

Todos son sistemas del poder y de producción de poder creados por otros para controlar las personas, los movimientos y sus actividades. Todo se interpreta a la luz de la peligrosidad real o potencial del sujeto.

Sistemas que capturan una imagen, extraen datos de ella, comparan con bases de datos y deciden la propia identidad: factores físicos, dactilares, la estructura facial, la palma de la mano, la retina, el ADN, el olor corporal, patrones de voz, la firma o los movimientos bruscos o marcados.

Sistemas de observación y control de las personas y sus actividades y espacios que ocupan: cámaras de video vigilancia; el sistema de posicionamiento global, vía satélite; el seguimiento de personas a partir del registro de la emisión de ondas electromagnéticas que es la voz; sistemas de seguimiento informático por medio de correos electrónicos "troyanos". 
Tecnologías basadas en imágenes o registros que ayudan a decodificar la información 'oculta' en determinados espacios, como barreras físicas, muros o ropas, fotografías y videos, huellas o restos de fluidos corporales que permanecen ocultos a simple vista; movimientos de los cuerpos, respiración; sistemas que se usan para ver en la oscuridad o detectar droga a partir de la temperatura o las radiaciones que desprenden los sujetos o los objetos bajo vigilancia. (Requena Hidalgo, 2004, pág. 8).

Reflexionemos sobre este neo-panóptico en el ambiente educativo, donde se ha formulado el nuevo ejercicio del poder y su propia producción del saber. Lo vamos a llamar -al estilo de José Joaquín Brunner- miseria de la educación en una sociedad disciplinaria.

¿Qué es lo que caracteriza a la sociedad que produce una educación de miseria?

La propuesta de Foucault puede ser digerible -con cierta aproximación- a la historia moderna de la educación:

La historia de esta microfísica del poder punitivo sería entonces una genealogía o una pieza para una genealogía del 'alma moderna'. Es el funcionamiento de un poder que se ejerce sobre aquellos a quienes se castiga, de una manera más general sobre aquellos a quienes se vigila, se educa y corrige, sobre los locos, los niños, los colegiales, los colonizadores, sobre aquellos a quienes se sujeta a un aparato de producción y se controla a lo largo de toda su existencia. (1978, pág. $56)$. 
Por otro lado, sobre la base de esta genealogía del alma moderna "se han construido conceptos diversos..., se han delimitado campos de análisis..., se han edificado técnicas y discursos científicos, se ha dado validez a las reivindicaciones morales del humanismo...dando lugar a un saber posible, y el saber prolonga y refuerza los efectos del poder". (1978, pág. 36).

Veamos un ejemplo que producido en la década de los setenta y, salvando los tiempos en la interpretación libre, bien se podría aplicar a nuestro momento.

Chile, dictadura del 73 , con un régimen político cerrado, "impuesto por mecanismos de control y disciplinamiento de la sociedad, produce un cambio radical en la función que desempeña la cultura en esa sociedad" (Brunner, 1977, pág. 7) y en la educación, diríamos nosotros. Todo el sistema establece un control administrativo de la cultura y educación con el propósito de encuadrarlo dentro de parámetros ideológico-políticos que orientan la acción del régimen.

En este régimen político cerrado, "el dominio ejercido se funda en última instancia siempre en su capacidad de controlar al todo social a través del disciplinamiento, sometiéndolo para ello a la política del Estado". El Estado invade la sociedad a través de una red de disciplinas que controla "hasta el nivel microscópico- dice Brunner, la actividad de los individuos, de los grupos, instituciones, etc.". El orden se establece a partir "no del consenso sino por medio de una envolvente operación del poder". Todo para expandir la obediencia e incrementar la utilidad de los individuos. (1977, pág. 8). 
En este tipo de régimen cerrado, la educación es parte esencial del adoctrinamiento y, por lo tanto reproduce el orden social que se impone bajo una triple patología que afecta a regímenes de este tipo.

La primera, se excluye un aprendizaje en un clima de debate nacional. Se compromete la condición de verdad. El régimen produce poder a través de un estilo disciplinario de pensar, donde se "enfatiza la fortaleza y pureza de ciertos límites y esquemas de clasificación, antes que el ejercicio de la razón". (1977, pág. 9).

La segunda patología, se compromete la condición de libertad en la comunicación social, donde se enfatiza la rigidez en el estilo de roles y la sobrevaloración del mundo normativo.

Y la tercera, excluye la posibilidad de llevar a cabo el proceso de aprendizaje bajo una situación definida, comprometiendo la condición de justicia en la comunicación social; es decir, "enfatiza el carácter autoritario de las interacciones, la no refutabilidad de las órdenes, la comunicación asimétrica, un concepto no racional de obediencia, un sentimiento de frustración frente a las jerarquías y, en general, la identificación de toda norma con la fuerza que la respalda y no con la convicción que es capaz de generar". (1977, pág. 9).

Valga nuestra reflexión para detallar algunos elementos que -a vuelo de pájaro- podrían ser interpretados bajo esta óptica de Foucault y aplicada en un momento histórico:

Leyes educativas, sociales y culturales que se constituyen para el establecimiento del poder desde 
el Estado. El Estado lo controla todo. Impone y supervigila todo. No hay posibilidades de refutación.

Sistemas de adoctrinamiento ideológico a través de la movilidad y beneficios populistas.

Poder que produce poder: disciplinadamente estar en desacuerdo es estar en contra el régimen sin opción racional de argumentación.

Violencia contra una sociedad que busca la verdad, la libertad y la justicia. Sistema cerrado que obliga a pensar monolíticamente en un solo pensamiento.

El Estado lo designa todo y se respalda en una mayoría educadamente ignorante, peligro grave para cualquier democracia.

Elementos que reflejan los dos momentos desde los cuales reflexionamos con Foucault: el primero, la relación de la sociedad disciplinaria con el poder y transformada en sociedad de control; y el segundo, cómo esa manera de ser se refleja en la educación como mero adoctrinamiento de un régimen que se impone e impone ideas y formas de pensar y educar. ¿Democracia? Por ningún lado. Llámese lo que se llame: nunca democracia.

\section{¿Qué esperamos?}

Educación y democracia, dos conceptos que están íntimamente ligados entre sí, ya que es la universidad el espacio donde se forma el pensamiento crítico, donde se debe gestar el debate y de donde deben surgir las ideas y 
propuestas que lleven a transformar la sociedad, a sembrar auténtica democracia.

Lastimosamente esto no se da porque o privilegiamos una educación que prioriza lo mercantil, lo económico a lo humanístico, o seleccionamos una que aborde el dominio y posicionamiento del pensamiento a través de los más grandes avances científicos y tecnológicos; pero que hagan de la sociedad una sociedad panóptica o de control total.

Más allá de adquirir conocimiento, la universidad debe propiciar el cuestionamiento, el desarrollo creativo, y la participación activa en la vida pública, que garanticen precisamente el fortalecimiento de la democracia. En este sentido, es necesario analizar el rol que están asumiendo, docentes y estudiantes, dentro del quehacer educativo. Contribuye a esta reflexión, lo planteado por José Saramago (2010) quien citado por (González, 2012) manifiesta que:

Sin idealizar la institución, habría que tender a que el objetivo que lleva en el nombre -la universidad- al menos estuviera presente en las distintas facultades y se expresara, un espíritu abierto que obliga a reflexionar, que capacita para el análisis, implica dominio de los conceptos, información sobre lo que es el mundo en que vivimos, las distintas sociedades humanas, las contradicciones, la historia que nos ha hecho ser como somos, el pasado colectivo y el presente individual y plural que tenemos que levantar. Así, al final de una carrera universitaria podremos tener un ingeniero, sí, pero sobre todo un ciudadano consciente de serlo. (pág. 204). 
Esto nos lleva a preguntarnos si en verdad estamos contribuyendo a la formación de seres reflexivos, libres, que sean actores responsables y poseedores de su saber, que utilicen su capacidad transformadora para crear una sociedad más justa y democrática y, por encima de todo, al estilo de Saramago, ciudadanos conscientes de serlo. Aquí entran en juego las relaciones de poder, que implican según (Aguiló Bonet, 2009) "un conjunto de procesos de intercambio - tanto material como simbólico- desigual entre sujetos individuales o grupos sociales" (pág. 2), lo que nos lleva a reflexionar sobre el rol que ejercemos como docentes universitarios y a preguntarnos si desde nuestra posición "superior" ante los estudiantes, no estamos ejerciendo nuestro "poder" para imponer los conocimientos que a nuestro criterio son los que el alumno debe aprender y al mismo tiempo limitar su participación a ser simplemente receptores, sin una participación directa, reflexiva, crítica y constructiva sobre su propio proceso de formación.

En su libro "El Maestro Ignorante", Jacques Ranciere (1987) expone un punto de vista interesante a través de la historia de Jacotot, un maestro que juzga que no es necesario impartir conocimiento para enseñar; que cuestiona la educación tradicional que se limita a transmitir información académica; al mismo tiempo manifiesta que su objetivo no es enseñar a sus estudiantes a ser intelectuales sino libres pensadores, alegando que ningún conocimiento es superior a otro. Jacotot cuestiona a aquellos maestros que creen ser dueños de la verdad y el conocimiento, ya que según él, ellos son los responsables de transformar a la educación en un proceso entorpecedor, donde el instructor es el que tiene el poder y se siente superior al alumno. Por otro lado, argumenta que "el maestro ignorante" ve a sus 
pupilos como seres iguales, capaces de desarrollar sus propios potenciales.

Al igual que Ranciere, el pedagogo Paulo Freire se cuestionó en su momento sobre este aspecto. El propone un intercambio dinámico entre maestro y estudiante, donde ambos interactúan y aprenden. Para Freire (1969) la educación debería ser un proceso de emancipación. En su obra "La Pedagogía del Oprimido" critica el sistema educativo y lo compara con un proceso bancario en donde los maestros depositan conocimientos y los estudiantes son receptores pasivos que los memorizan, convirtiéndose así en objetos de instrucción sin conciencia crítica ni creatividad. Más aun afirma que la forma en la que se ha llevado la educación, ha sido responsable de la opresión, ya que obliga a las personas a encajar en el mundo y aceptarlo, sin hacer ningún cuestionamiento; propone un abordaje humanista donde la educación se convierta en un proceso liberador que despierte la conciencia y el pensamiento crítico y desde donde surja la democracia. Freire manifiesta que "solo existe saber en la invención, en la reinvención, en la búsqueda inquieta, impaciente, permanente que los hombres realizan en el mundo, con el mundo y con los otros" (pág. 52). Así pues, la universidad debería ser el lugar donde tanto alumnos como profesores puedan desarrollarse plenamente, donde puedan participar activamente compartiendo saberes, replanteando ideas diversas a través de una dinámica donde prime la tolerancia y el respeto del otro. Para Aguiló Bonet, 2009, la universidad debe contribuir a la democratización del saber, al desarrollo autónomo y a la construcción de un conocimiento intercultural y emancipador, que favorezcan la búsqueda de una vida digna a través de la docencia, la investigación y el pensamiento. 
Volvemos a preguntarnos: ¿qué esperamos de la relación educación (universidad)-democracia?

Esperamos ver crecer al ser humano dentro de un ambiente de tolerancia y respeto. Ver crecer la sociedad donde ésta se pueda llamar democrática. Satisfacer las necesidades del hombre desde lo que él es y pretende. Investigar, estudiar, hacer universidad con el afán de que el hombre sea y se sienta más ciudadano en un mundo y casa común con dedicación y responsabilidad democráticas.

Esperamos una educación universitaria que cree ciudadanos que crean en ambientes democráticos en una sociedad global.

\section{Bibliografía}

AFP. (12 de Noviembre de 2015). Corea del Sur paralizada para no desconcentrar a sus alumnos en examen. El Universo, págs. 1-2.

Aguiló Bonet, A. (2009). La universidad y la globalización alternativa: justicia cognitiva, diversidad epistémica y democracia de saberes. Nómadas, 5-28.

Ariza, L. (6 de Noviembre de 2011). Desafíos del corazón. EL PAís, págs. 1-2.

Brunner, J. (1977). La miseria de la educación y la cultura en una sociedad disciplinaria. Nueva Sociedad, 81-94.

Carlin, J. (8 de Noviembre de 2015). El estudiante eunuco. EL PAís, págs. 1-2. 
Carvajal, I. (2016). Universidad sentido y crítica. Quito: Centro de publicaciones. PUCE.

Corral, F. (4 de Noviembre de 2015). Veloz, precaria y superficial. El Comercio, págs. 1-2.

Escolar, C. (2004). Pensar en/con Foucault. Cinta Moebio, 93-100.

Fernández, B. (11 de Enero de 2017). Sociedad líquida. Sociedad líquida, págs. 1-2.

Foucault, M. (1978). Vigilar y castigar. México: Siglo XXI Editores S.A.

Freire, P. (1969). La pedagogía del oprimido. Santiago.

García Canal, M. (26 de noviembre de 2011). Foucault y el poder. La sociedad disciplinaria. Cuenca, Azuay, Ecuador: Universidad de Cuenca.

González, J. (2012). Democracia y Universidad. Estudios: Filosofía, Historia, Letras. 203-209.

Gutiérrez Lozano, C. (2013). John Henry Newman y la idea de la Universidad. Estudios, 167-179.

Luna, M. (29 de Noviembre de 2015). Frustración y bronca. El Comercio, págs. 1-2.

Marías, J. (16 de Julio de 2015). Si todo, todo. EL PAÍS, págs. $1-2$.

Martínez, D. (12 de Enero de 2017). Hacia una universidad líquida: homenaje a Zygmunt Bauman. Obtenido de UniverSídad: http://www.universidadsi.es/hacia-unauniversidad-liquida-homenaje-zygmunt-bauman/

Montero, R. (29 de Septiembre de 2015). Corazones que piensan. EL PAÍS, págs. 1-2. 
Nussbaum, M. (2012). Sin fines de lucro. Por qué la democracia necesita de las humanidades. Madrid: Katz editores.

Ordine, N. (2014). La utilidad de lo inútil. Manifiesto. Barcelona: Acantilado.

Ranciere, J. (2003). El maestro ignorante. Cinco lecciones sobre la emancipación intelectual. Barcelona: Laertes S.A. Ediciones.

Requena Hidalgo, J. (2004). De la 'sociedad disciplinaria' a la 'sociedad de control': la incorporación de nuevas tecnologías a la policía. Scripta Nova, 1-13.

Zalles, J. (18 de Noviembre de 2015). Quijotes pero no locos. El Comercio, págs. 1-2. 